\title{
Critical Metals Recovery Using Biotechnological Methods
}

\author{
Marian BUTU ${ }^{1}$, Steliana RODINO ${ }^{1 *}$, Alina BUTU ${ }^{1}$ \\ ${ }^{1}$ National Institute of Research and Development for Biological Sciences, Bucharest, Romania, Splaiul \\ Independentei, no 296, P.0. Box no 17-16, 060031, Bucharest, Romania, Tel. / Fax. +4021/220 0880 \\ * corresponding author: steliana.rodino@yahoo.com
}

Bulletin UASVM Animal Science and Biotechnologies 73(2)/ 2016

Print ISSN 1843-5262; Electronic ISSN 1843-536X

DOI:10.15835/buasvmcn-asb: 12252

\begin{abstract}
Critical metals are metals whose availability is essential for high-technology in medical and electronics industry, defense applications, but vulnerable to politically or economically driven fluctuations in supply, mainly due to their uneven geographical distribution. Nowadays, in order to meet the current challenges of sustainability, an innovative and modern approach to the extraction, use and recovery of these metals must be developed.The aim of the research is to extend Europe's effective resource base for critical metals from primary and secondary resources for critical metals, thus transforming waste into a valuable raw material. This article explores the potential application of microbial biotechnology methods for the recovery of critical metals. Laboratory experimental studies demonstrated that there is a real possibility to further develop and improve the process of bioleaching, designed for bioremediation of heavy metals and pollutants, optimising its application within a circular economy approach for critical metals recovery.Scientific research regarding the potential responses of microbial consortia to specific critical metals and novel possible microorganisms with biotechnological potential for the recovery of critical metals from various sources (including mine wastes and tailings, residual waters and waste electrical and electronic equipment, also) is essential for determining the role of microbial communities in the achievement of new sources for critical metals.
\end{abstract}

Keywords: bioleaching, critical metals, metals recovery, microbial communities

\section{INTRODUCTION}

The term "critical raw material" was first introduced in US by the "Strategic and Critical Materials Stock Piling Act" from 1939 (Legislative Councel, 1939). Critical metals belong to the category of critical raw materials as described by the European Union, beginning with the year 2010. The European Commission defines raw material criticality as follows (European Commission, 2010): "To qualify as critical,a raw material must face high risks with regard to access to it, i.e.high supply risks or high environmental risks, and be of high economic importance. In such a case, the likelihood that impediments to access occur is relatively high and impacts for the whole EU economy would be relatively significant".These are metals whose availability is essential for the development of high-technology end-products in medical and electronics industry and defense applications. In the same time, critical metals are vulnerable to politically or economically driven fluctuations in supply, mainly due to their uneven geographical distribution (European Comission 2014, US Department of Energy 2011).

Nowadays, in order to meet the current challenges of sustainability, innovative and modern approaches to the extraction, use and recovery of critical raw materials is a must. One option is to study the existing opportunities for developing more efficient biological processes in molecular biology and ecology, based on the 
practical application of bioaccumulation by microorganisms, which is already considered as alternative for metal recovery and remediation (Takumi et al., 2015).The methods used include engineering of microbe-metal interactions for recovering scarce and critical metals such as rare earth elements, platinum group metals, beryllium (Be), chromium $(\mathrm{Cr})$, cobalt $(\mathrm{Co})$, gallium (Ga), indium (In), lithium (Li), niobium $(\mathrm{Nb})$ and tungsten (W). The importance of biotechnology has been realized in resource recovery of metals from solid and liquid wastes, particularly due to the low abundance and market potential of critical elements, and the ability of microorganisms to selectively sequester diffuse elements. Development of new processes for the extraction and recovery of metals from mine tailings, stored solid wastes, oxide ores, end-ofuse products (e.g., e-waste components, spent batteries, spent catalysts), solid municipal waste incinerators, contaminated sites, medical waste, sewage sludge, process streams and industrial effluents using microorganisms is expected in the coming years (Nancharaiah et al., 2016).

In this study are presentedpreliminary studies on the recovery of critical metalsbybiotechnological methods, starting with screening and isolation of naturally occurring microorganisms existing in mining residues collected from our country. The experiments described belong to a wider research towards the recognition of microbial functional communities and the assessment of their mineralizing potential for critical metals. The main objectives of the researchare to investigate on fungal strains surviving in the soil surrounding mines areas, and to study their possible capacity to absorb or capture and reduce selected metal in soil and water. The aim of the study was to isolate, identify and characterize these indigenous microorganisms as well as their application potential to recovery of raw materials from the mentioned sources.

\section{MATERIALS AND METHODS}

\section{Sampling}

Soil samples from mining areas were collected in sterile caped bottles and were stored at $4-8^{\circ} \mathrm{C}$, in the refrigerator, until further use. The samples were collected from 20 to maximum $100 \mathrm{~cm}$ below the ground level.

\section{Chemical reagents}

The stock solutions of critical metals were prepared by dissolving metal salts in distilled waterand afterwards were sterilized by filtration through $0.22 \mu \mathrm{m}$ pore-size Merck Millipore sterile filters. The working metal solutions of 5, 10, 25, 50 and $100 \mathrm{mg} \mathrm{L}^{-1}$ concentrationswere prepared from the stock solutions. The tested metals were as follows:Magnesium nitrate hexahydrate $\mathrm{Mg}\left(\mathrm{NO}_{3}\right)_{2}$ - $6 \mathrm{H}_{2} \mathrm{O}$; Gallium nitrate hydrate $\mathrm{Ga}\left(\mathrm{NO}_{3}\right)_{3} \cdot \mathrm{xH}_{2} \mathrm{O}$; Sodium tungstate dihydrate, $\mathrm{Na}_{2} \mathrm{WO}_{4} \cdot 2 \mathrm{H}_{2} \mathrm{O}$; Palladium nitrate dihydrate $\mathrm{Pd}\left(\mathrm{NO}_{3}\right)_{2} \cdot 2 \mathrm{H}_{2} \mathrm{O}$; Platinum cyanide, $\operatorname{Pt}(\mathrm{CN})_{2}$.

\section{Media used}

Horikoshi media, soil extract media,potato dextrose agar (PDA) and potato dextrose broth (PDB) were used for isolation and further maintenance of the fungal strains.

The soil extract media contains $500 \mathrm{~mL} / \mathrm{L}$ soil extract and $15 \mathrm{~g} / \mathrm{L}$ agar. The soil extract was prepared by mixing $1000 \mathrm{~g}$ of soil extract with $2 \mathrm{~L}$ of double distilled water and incubating overnight at room temperature. After filtration and centrifugation at $15000 \mathrm{rpm}$, the supernatant was sterilized by autoclaving three times. The obtained soil extract was used for the preparation of the soil extract media (Karelováet al., 2011).

The Horikoshi medium contained: $10 \mathrm{~g}$ glucose, $5 \mathrm{~g}$ yeast extract, $5 \mathrm{~g}$ polypeptone, $1 \mathrm{~g} \mathrm{~K}_{2} \mathrm{HPO}_{4}, 0.2 \mathrm{~g}$ $\mathrm{MgSO}_{4} \cdot 7 \mathrm{H}_{2} \mathrm{O}, 15 \mathrm{~g}$ agar and $900 \mathrm{~mL}$ distilled water. Before the use it was aseptically added $100 \mathrm{ml}$ of $10 \% \mathrm{Na}_{2} \mathrm{CO}_{3}$.

Potato-dextrose agar (PDA) was used for isolation maintenance and preservation of the fungal isolates. Its composition was as follows ( $\mathrm{g} \mathrm{L}^{-1}$ ): potatoes, 200; dextrose, 20; agar, 20 and adjusted to $\mathrm{pH}$ 5.0.

\section{Sample culturing and fungal isolation}

Sterile saline water was poured in Erlenmeyer flasks containing an exact quantity of soil powder. The flasks were shaken on an orbital shaker for 60 minutes, and then left still for 24 hours, at room temperature, with occasional shaking. Finally, the suspension was filtered through Whatman no.1 filter paper (Rodino et al, 2016). Serially diluted aliquots $(0.1 \mathrm{~mL})$ were used as inoculum on different culture agar, prepared after the recipes described above. The plates were incubated at 25$28{ }^{\circ} \mathrm{C}$. Grown colonies of fungi were selected and 

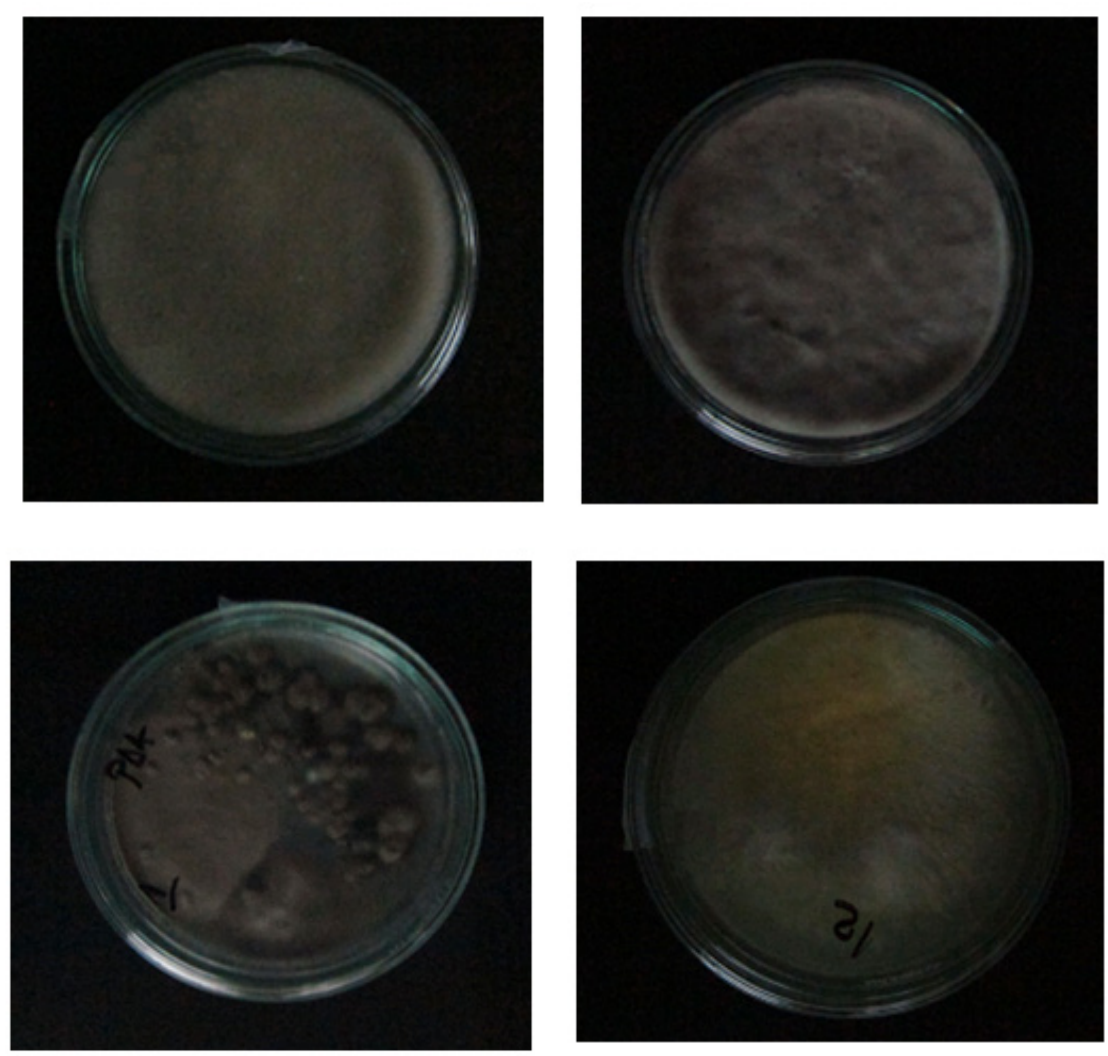

Figure 1. The aspect of fungal isolates on PDA

purified, and then their ability to grow on PDA supplemented with different concentrations of critical metals was observed. Fungal isolates were maintained by sub-culturing.Stock cultures were maintained at $4{ }^{\circ} \mathrm{C}$ on preservation medium (PDA) after incubation at $28-30^{\circ} \mathrm{C}$ until visible growth.

\section{Screening metal resistant fungal isolates}

The tolerance of selected fungal isolates to critical metals was tested by diffusion method. The isolated fungi were cultured on potato dextrose agar (PDA) containing increasingconcentrations of critical metals and were subsequently incubated at room temperature, until the control colony reached the margins of the Petri plate. The growth of fungal colonies on the plates containing culture media with no metals was considered as control. The growth of fungal mycelium was observed, and the isolate which showed high resistance in metal amended agar was selected for further study.

The quantitative evaluation was performed in Erlenmeyer flasks $(200 \mathrm{ml})$ containing $100 \mathrm{ml}$ of Potato dextrose broth medium supplemented with increasing critical metals concentrations. The flasks were inoculated with the tested isolates and incubated at $28-30^{\circ} \mathrm{C}$. After the incubation period, the fungal cultures were filtrated using Whatman filter paper no. 1 , washed twice and dried at $80^{\circ} \mathrm{C}$ to constant weight.

\section{RESULTS AND DISCUSSION}

After repeated transfer and purification of the initial cultures, 4 fungal strains were isolated as pure cultures (Figure 1). These fungal isolates, named BcRF13-1, BcRF13-2,BcRF13-3,BcRF13-4, were selected to be used in further studies, described in the following paragraphs.

The isolated fungi were cultured on potato dextrose agar (PDA) containing increasing concentrations of critical metals and were subsequently incubated at room temperature. Data indicate a decrease in the number of isolated fungal strains tolerant to critical metals at higher concentration.

The fungal isolates showed low tolerance to Gallium and Wolfram, with a low growth of BCRF 13-1 and BCRF 13-3 on Gallium supplemented media, and respectively BCRF 13-3 for tungsten, but at a very low concentration of the metals in the culture media $\left(5 \mathrm{mg} \mathrm{L}^{-1}\right)$. Encouraging results 
Tab. 1.Tolerance of fungal isolates to critical metals and concentrations

\begin{tabular}{|c|c|c|c|c|c|c|}
\hline \multirow{2}{*}{$\begin{array}{l}\text { Fungal isolate } \\
\text { code }\end{array}$} & \multicolumn{6}{|c|}{ Concentration (mg L ${ }^{-1)}$} \\
\hline & 0 & 5 & 10 & 25 & 50 & 100 \\
\hline & \multicolumn{6}{|c|}{ Magnesium } \\
\hline BCrF 13-1 & ++++ & + & + & + & + & - \\
\hline $\mathrm{BCrF} 13-2$ & ++++ & +++ & +++ & ++ & + & - \\
\hline $\mathrm{BCrF} 13-3$ & ++++ & - & - & - & - & - \\
\hline \multirow[t]{2}{*}{ BCrF 13-4 } & ++++ & + & - & - & - & - \\
\hline & \multicolumn{6}{|c|}{ Palladium } \\
\hline $\mathrm{BCrF} 13-1$ & ++++ & - & - & - & - & - \\
\hline BCrF 13-2 & ++++ & ++ & + & + & + & - \\
\hline $\mathrm{BCrF} 13-3$ & ++++ & +++ & + & + & - & - \\
\hline \multirow[t]{2}{*}{$\mathrm{BCrF} 13-4$} & ++++ & - & - & - & - & - \\
\hline & \multicolumn{6}{|c|}{ Platinum } \\
\hline $\mathrm{BCrF} 13-1$ & ++++ & - & - & - & - & - \\
\hline $\mathrm{BCrF} 13-2$ & ++++ & ++ & ++ & + & + & - \\
\hline BCrF 13-3 & ++++ & - & - & - & - & - \\
\hline \multirow[t]{2}{*}{$\mathrm{BCrF} 13-4$} & ++++ & - & - & - & - & - \\
\hline & \multicolumn{6}{|c|}{ Gallium } \\
\hline BCrF 13-1 & ++++ & + & - & - & - & - \\
\hline $\mathrm{BCrF} 13-2$ & ++++ & - & - & - & - & - \\
\hline $\mathrm{BCrF} 13-3$ & ++++ & + & - & - & - & - \\
\hline \multirow[t]{2}{*}{$\mathrm{BCrF} 13-4$} & ++++ & - & - & - & - & - \\
\hline & \multicolumn{6}{|c|}{ Wolfram/tungsten } \\
\hline BCrF 13-1 & ++++ & - & - & - & - & - \\
\hline $\mathrm{BCrF} 13-2$ & ++++ & - & - & - & - & - \\
\hline $\mathrm{BCrF} 13-3$ & ++++ & + & - & - & - & - \\
\hline $\mathrm{BCrF} 13-4$ & ++++ & - & - & - & - & - \\
\hline
\end{tabular}

were obtained in terms of tolerance of PGM group metals, namely Platinum and Palladium, with moderate growth for both metals of the strain $\mathrm{BCrF} 13-2$. $\mathrm{BCrF} 13-3$ showed a high growth at a concentration of $5 \mathrm{mg} \mathrm{L}^{-1}$ palladium in the culture medium.

Furthermore, the fungal isolates $\mathrm{BCrF} 13-1$, 13-2 and 13-3, were cultivated in liquid medium supplementedwith different critical metals salts at different concentrations(5-100 $\left.\mathrm{mg} \mathrm{L}^{-1}\right)$. Negative control was represented by samples with no critical metals added in cultivation media. As can be seen in Figure 2, it could be observed an obvious decreaseof the growth of tested fungal isolates when the critical metals concentration in culture medium increased.

Naturally occuringfungal isolates own a better potential to be used as bioleaching component in a consortia because they are the result of a longterm process of adaptation to soils with extreme properties such as high concentration of metals (Gaur et al., 2004). At this moment, the fungal strains are used widely in industrial fermentation and bioremediation (Rani et al., 2014), being preferred over other organisms (such as bacteria and yeasts) because they are easier to remove from liquid substrates.

\section{CONCLUSION}

Laboratory experimental studies, from scientific literature and preliminary screening from the present work, demonstrated that there is a real possibility to further develop and improve the process of bioleaching, designed for bioremediation of heavy metals and pollutants, optimising its application within a circular 


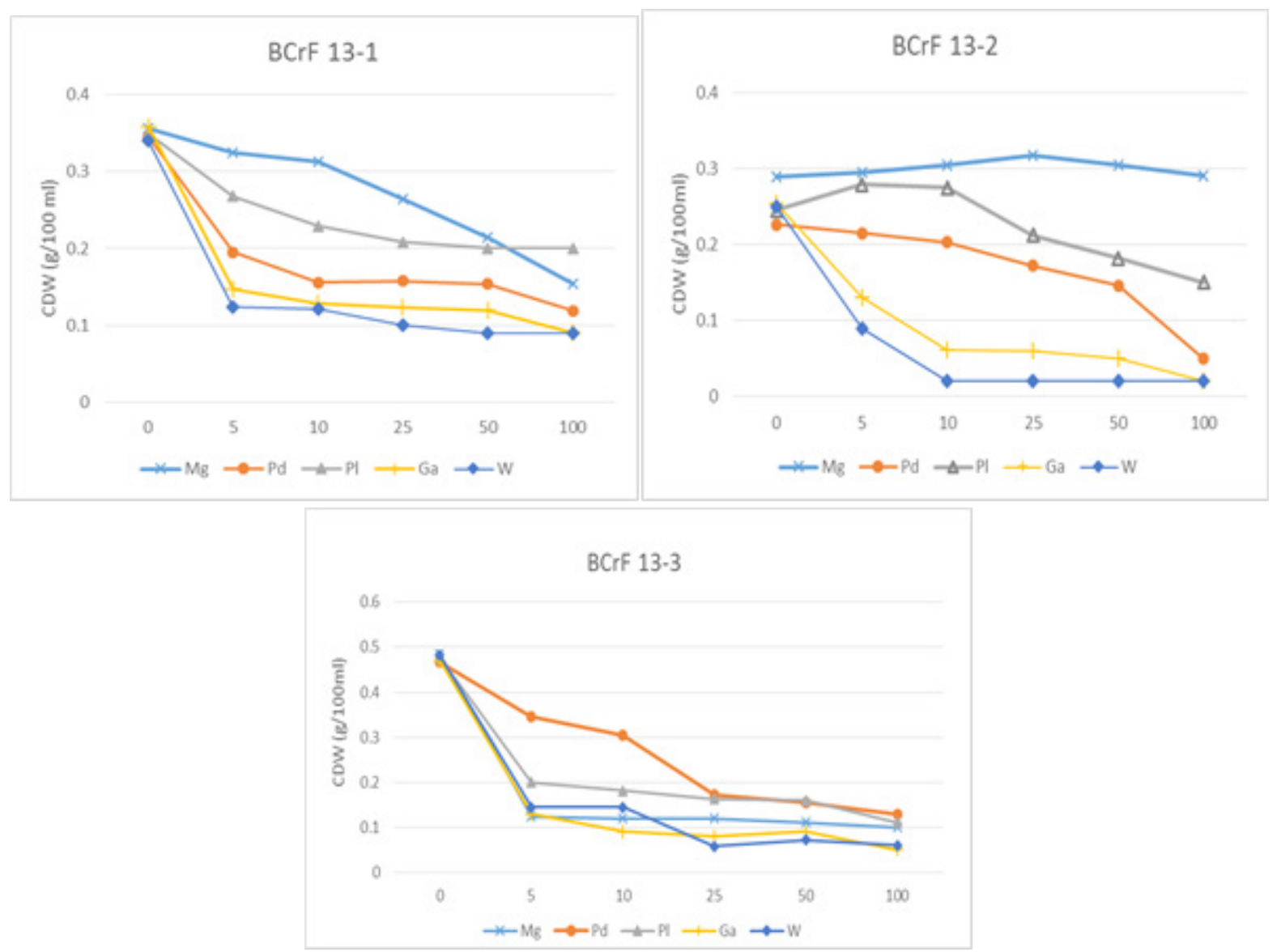

Figure 2. Cell dry weight of fungal isolates influenced by different concentrations of critical metals

economy approach for critical metals recovery. Scientific research regarding the potential responses of microbial consortia to specific critical metals and novel possible microorganisms with biotechnological potential for the recovery of critical metals from various sources (including mine wastes and tailings, residual waters and waste electrical and electronic equipment, also), is essential for determining the role of microbial communities in the achievement of new sources for critical metals.

\section{Acknowledgments}

This work was supported by a grant of the Romanian National Authority for Scientific Research and Innovation, CCCDI - UEFISCDI, project number 18/2016, within PNCDI III.

\section{REFERENCES}

1. European Commission (2010). Critical Raw Materials for the EU. Technical Report, European Commission (Enterprise and Industry), Brussels, Belgium;
2. European Commission (2014). Critical raw materials for the EU. Report of the Ad-hoc Working Group on defining critical raw materials, <http://ec.europa.eu/ enterprise/ policies/raw-materials/files/docs/;

3. Gaur A, Adholeya A (2004). Prospects of arbuscular mycorrhizal fungi in phytoremediation of heavy metal contaminated soils.Current Sci 86:528-534;

4. Karelová E, Harichová J, Stojnev T, Pangallo D, Ferianc P (2011). The isolation of heavy-metal resistant culturable bacteria and resistance determinants from a heavy-metalcontaminated site, Section Cellular and Molecular Biology, Biologia, 66 (1):18-26;

5. Legislative Councel (1939). Strategic and Critical Materials Stock Piling Act.Technical Report, 50U.S.C.98, Office of the Legislative Council,U.S.House of Representatives,Washington, D.C.;

6. Nancharaiah YV, Venkata Mohan S, Lens PNL (2016). Biological and bioelectrochemical recovery of critical and scarce metals, Trends in Biotechnology, 34 (2): 137 - 155;

7. Rani B, Kumar V, Singh J, Bisht S, Teotia P, Sharma S, Kela $R$ (2014). Bioremediation of dyes by fungi isolated from contaminated dye effluent sites for bio-usability. Brazilian Journal of Microbiology, 45(3): 1055-1063;

8. Rodino S, Butu A, Fidler G, Butu M (2016). Preliminary screening of bacterial isolates from mining wastes.Studia 
Universitatis "Vasile Goldiș", Seria Ştiințele Vieții, 26 (2): 293-297;

9. Takumi H, Mitsuo Y (2015). A New Fungal Isolate, Penidiella sp. Strain T9, Accumulates the Rare Earth Element Dysprosium Appl. Environ. Microbiol., 81 (9): 3062-3068;
10. US Department of Energy(2011). Critical Materials Strategy. Available online at: http://energy.gov/sites/ prod/files/ DOE_CMS2011_FINAL_Full.pdf2011. 